\title{
Resin Bonding and Strength Development in Offset Papers
}

\author{
By Charles G. Weber, Merle B. Shaw, Martin J. O'Leary, \\ and Joshua K. Missimer
}

\begin{abstract}
A series of experimental offset papers was made in which the strength and resistance to surface pick were developed mainly by bonding the fibers with a synthetic resin instead of by the conventional beating. The papers were made from three widely different furnishes of commercial wood pulps, and the principal bonding agent was melamine-formaldehyde resin. In all instances, the resin-bonded papers were superior with respect to curling, oil absorption, folding endurance, and resistance to tear to gel-bonded control papers with comparable bursting strength and resistance to pick. Expansion also was improved in sulfite-soda papers. Only small amounts of resin were required to greatly improve the strength of papers composed principally of short-fibered filler pulps.
\end{abstract}

\section{Introduction}

Maximum strength in wood-fiber papers is customarily developed by beating with the formation of gel-like bonds formed by the hydration associated with beating. For the best results in offset printing, paper must be made with a minimum of beating, because the formation of gel on the fibers must be carefully controlled. The development of maximum strength by hydration promotes some of the most troublesome properities of paper encountered in offset printing, namely, high expansion, excessive curling, slow oil absorption, and low opacity.

In experimental manufacture of offset papers at the National Bureau of Standards the use of a synthetic resin, widely used for imparting wet strength to paper, has been extended to a new field. Resin bonds between the fibers are substituted for the conventional gel-like bonds formed by hydration. The resin bonding made it possible to develop suitable strength with a minimum of adverse effect on the other properties of the paper.

Maximum strength was developed in wood-fiber papers by resin bonding with only a fraction of the beating required to develop comparable strength by beating alone.
By using resin it was also possible to develop suitable strength when using high contents of filler pulps that do not lend themselves readily to hydration. This is important because these pulps contribute to low curl and expansivity and good oil absorption in paper.

It was possible to obtain much higher folding endurance, a very desirable property, without the undesirable effects that accompany the building up of folding strength by hydration. The results were secured in experimental papers made in the Bureau's semicommercial-scale paper mill by using different combinations of typical commercial wood pulps. A series of papers was made from each fiber furnished, with controlled variations in beating, with and without synthetic-resin bonding. The work was carried on with the counsel of an advisory committee of technical representatives under the chairmansbip of R. F. Reed, director of research, Lithographic Technical Foundation. Previous publications resulting from research work at the Bureau with the cooperation of the advisory committee contain information on the manufacture and treatment of offset papers for optimum results in offset printing [1 to 10$].{ }^{1}$

\footnotetext{
${ }^{3}$ Figures in brackets indicate the literature references at the end of this paper.
} 


\section{Experimental Paper-making Equipment}

The paper-making equipment at the Bureau is semicommercial in size, and is adapted to the experimental manufacture of papers under conditions that simulate those of typical industrial plants. Detailed descriptions and photographs of the essential equipment are contained in previous publications $[11,12,13]$. The equipment used in this particular work consisted essentially of a 50-lb beater with copper-lined tub and manganese-bronze bars and plate; a jordan refiner with bars of bronze and steel alloy, a four-plate, flat screen; a 29-in. Fourdrinier paper-making machine with a wire $33 \mathrm{ft}$. long, two presses, nine 15 in. dryers, a machine calender stack of seven rolls, and a reel; and a five-roll supercalender.

\section{Fibrous Raw Materials}

Inasmuch as the purpose of this investigation was to explore the possibilities of substituting resin bonding for the effects of hydration in developing strength, only three types of commercial wood pulps were used. The following pulps were chosen:

1. Bleached sulfite, made by cooking eastern spruce wood in a solution of calcium bisulfite. This was a relatively standard quality of pulp such as is widely used in offset papers. It is composed of relatively long, strong fibers that hydrate rather readily with beating.

TABLE 1.-Test data on pulps used in experimental papers

\begin{tabular}{|c|c|c|c|c|c|c|c|c|}
\hline Kind of pulp & 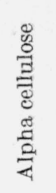 & 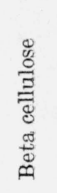 & 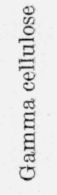 & 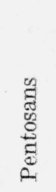 & 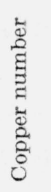 & कี & 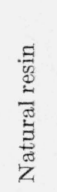 & 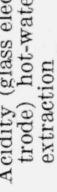 \\
\hline & $\begin{array}{l}\text { Per- } \\
\text { cent } \\
84.4\end{array}$ & $\begin{array}{r}\text { Per- } \\
\text { cent } \\
3.6\end{array}$ & $\begin{array}{l}\text { Per- } \\
\text { cunt } \\
12.0\end{array}$ & $\begin{array}{l}\text { Per- } \\
\text { cent } \\
4.2\end{array}$ & 1.3 & $\begin{array}{c}\text { Per- } \\
\text { cent } \\
0.2\end{array}$ & $\begin{array}{l}P c r- \\
\text { cent }\end{array}$ & $p H$ \\
\hline Deciduous wood & & & & & & & & \\
\hline sulfite & 83.6 & 10.9 & 5.5 & 6.0 & 1.0 & .2 & .1 & 6.2 \\
\hline Soda.... & 80.7 & 16. 2 & 3.1 & 15.1 & 1.5 & 1.8 & .4 & 8.5 \\
\hline
\end{tabular}

2. Bleached deciduous-wood sulfite, a shortfibered filler type of pulp made by cooking deciduous woods in a solution of calcium bisulfite. The fibers are soft and resilient and impart desirable resilience and absorptiveness to printing papers.
However, they are tender and are inclined to break up rather than to hydrate during beating.

3. Soda pulp, another filler pulp made by cooking deciduous woods in a solution of caustic soda. The fibers are characteristically soft and bulky, comparable to deciduous-wood sulfite, but somewhat stronger and less resilient. They do not hydrate readily.

The chemical characteristics of these pulps are given in table 1 .

\section{Manufacturing Procedure}

The general procedure comprised the making of papers with strengths developed by controlled variations in beating, without resin and with synthetic-resin binders. The comparative results with a number of different resins were first investigated with the more nearly conventional beater furnish of 75-percent sulfite-25-percentsoda pulps. Subsequently other furnishes were explored in a similar manner.

Fifty pounds of pulp was used for each machine run. Before the stock was furnished to the beater in each instance, the roll was raised above the bedplate a definite number of turns. The position of the beater roll is expressed as the number of turns of the handwheel above $(+)$ or below zero setting, which is the point of contact between the roll and the bedplate. One turn moves the roll 0.008 inch. The beating pattern with respect to sequence and time intervals of roll settings is shown in figure 1.

The beaten stock was dropped directly to a chest from where it was pumped via the stuff box, through the jordan and screen to the machine without the use of a machine chest. The stuff box was of the regulating type with constant head over an adjustable orifice. The jordan was used as a mixer only, with the same setting for all papers.

Melamine-formaldehyde resin was the standard bonding agent. It was added in the form of a colloidal solution made by dissolving the powdered resin in warm water acidified with hydrochloric acid. The solution was added continuously at uniform rate to the paper-making stock just before it entered the head box of the paper machine. The temperature of the stock was maintained at $90^{\circ} \pm 2^{\circ} \mathrm{F}$. One percent of rosin size was used in each of the papers, hence sizing 


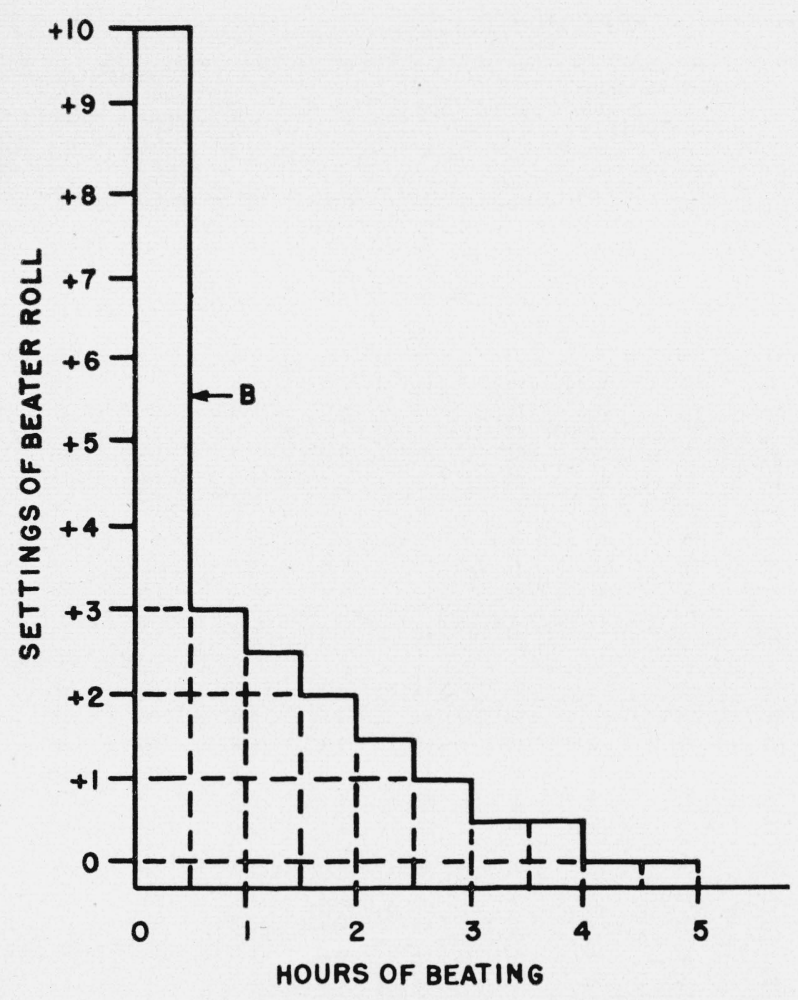

FIGURE 1. Standard practice of lowering the beater roll for all experimental papers.

$B$, Pattern of beating curve for all papers. Value for roll settings are turns of the handwheel above $(+)$ contact $(0)$ of roll with bedplate. One turn moves the roll 0.008 in. Lighter bar down at start.

was not a variable. It was precipitated with papermaker's alum, $\mathrm{Al}_{2}\left(\mathrm{SO}_{4}\right)_{3}$, which was used to control the $\mathrm{pH}$ of the stock. No filler was used. The finish imparted by the small machine calender was relatively low; therefore, the papers were given light supercalendering to obtain a smoothness comparable to commercial "machine finish."

\section{Sampling and Testing}

The method of sampling paper from a machine run in the paper mill was as follows: The paper wound on the reel of the paper machine during the test period was slit across the web, thereby being converted into a stack of sheets. The stack was then cut so as to give an entire cross section of the sheets for sampling. The resultant stack was divided into seven parts. From the first part, 13 sheets were laid out as the first sheets of 13 packs to be built up. From the second part,
13 sheets were likewise distributed as the second sheets of the packs. From each of the seven parts a sheet was added to each pack. The procedure was then repeated until all the paper had been distributed into the 13 packs. The oddnumbered (1-3-5-7-9-11-13) packs were then assembled, one above the other, to make one bundle of paper, and similarly the even-numbered packs to make another. From these bundles, sheets were taken for the test samples.

All physical and chemical tests of the pulps and papers referred to herein were made in accordance with the Standard Methods of the Technical Association of the Pulp \& Paper Industry, ${ }^{2}$ except air permeability. This property was determined with a Carson Precision Permeability Tester [14], which measures the rate of air flow through the paper per unit of area with a pressure difference of $1 \mathrm{~g} / \mathrm{cm} .^{2}$ The $\mathrm{pH}$ of mill waters at the beater, stuff box, and head box was determined electrometrically with a quinhydrone electrode.

A Set of the papers comprising sheets from each machine run was printed in six colors by the offset process at the Coast and Geodetic Survey to get information on relative printing qualities. The papers were conditioned in accordance with the best recommended practice for control of moisture in multicolor printing [4] and printed in a press room with controlled humidity and temperature.

\section{Description of Experimental Papers}

Papers were made of 75-percent-sulfite-25percent-soda pulps, 75-percent-soda-25-percentsulfite pulps, and 75-percent-deciduous-wood sulfite-25-percent-standard-sulfite pulps. The procedure was to make control papers from each furnish with three different degrees of beating, and then repeat each control run several times with different amounts of bonding resin. Four synthetic resins were tried in exploratory machine runs. Since appreciably better results were obtained with melamine-formaldehyde resin than with the others, that resin was selected as the standard bonding agent for this investigation.

The properties of the typical papers made are shown in table 2 .

\footnotetext{
2 Available from the Association headquarters at 122 East Forty-Second Street, New York 17, N. Y. The methods specify the number of specimiens for each test as well as other details of testing.
} 
TABLE 2. Properties of experimental offset papers

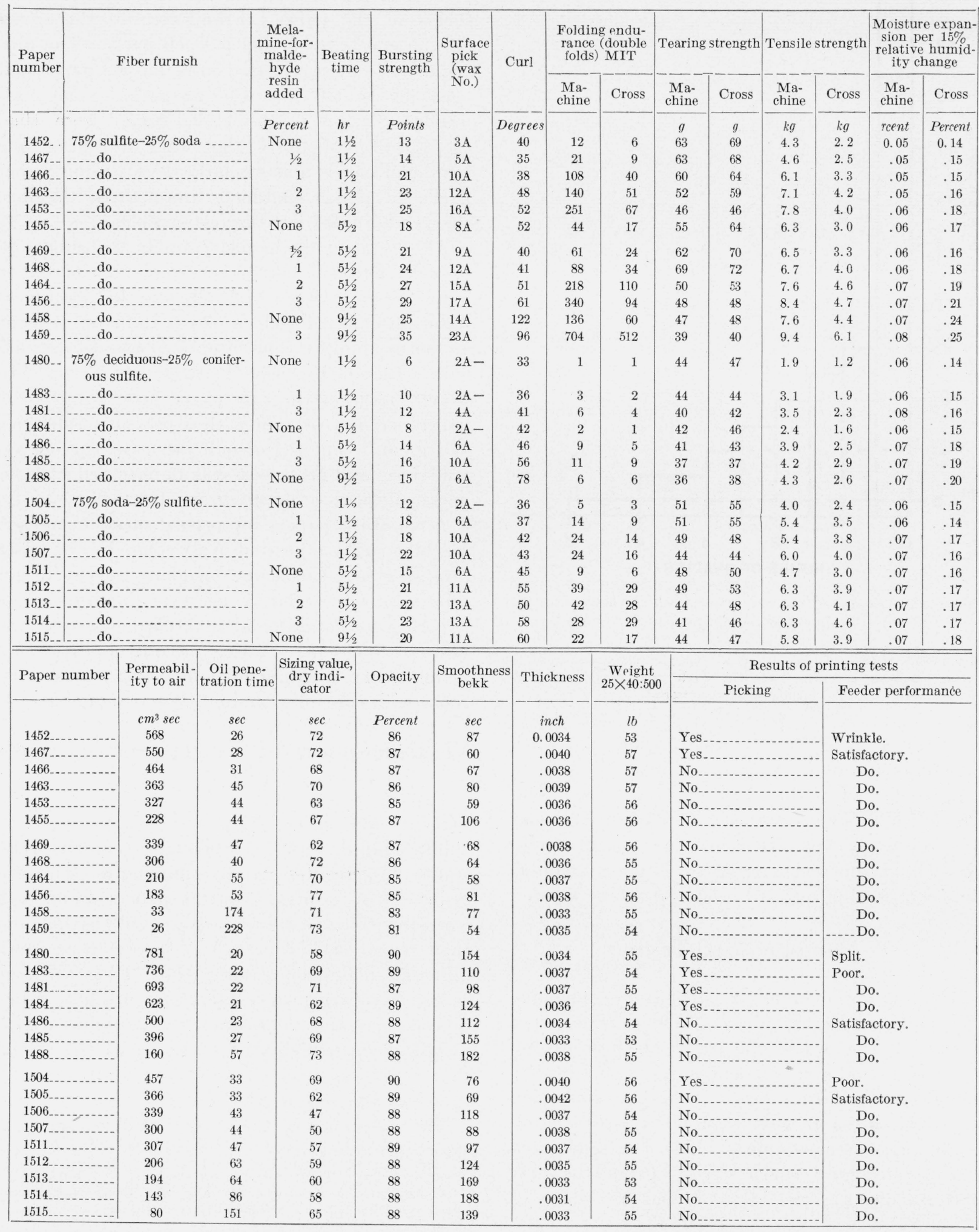

a Tests made in accordance with the Standard Methods of the Technical Association of the Pulp and Paper Industry, 122 East Forty-Second Street, New York 17, N. Y. 


\section{Interpretation and Discussion of Data}

The first objective of this work was to find the possible advantages of developing strength by resin bonding over the development of comparable strength by "hydration." By referring to the data on the 75-percent-sulfite-25-percent-soda papers in table 2 , it will be seen that 2 percent of bonding resin and only $1 \frac{1}{2}$ hours of beating, which amounted to mixing only, developed bursting strength and surface pick comparable to those achieved by $9 \frac{1}{2}$ hours of beating without resin. One and one half hours of beating with 3 percent of resin achieved far better strength than was obtained by hydration alone, even with the most drastic beating.

The advantages of resin-bonding versus gelbonding, or hydration, for developing strength in printing papers are shown graphically in figures 2 and 3 . In figure 2, three papers of like bursting strength are compared graphically. The bursting strength of paper $C$ was developed by $9 \frac{1}{2} \mathrm{hr}$ of beating. For paper $R_{3}$, the bursting strength was developed with 3 percent of resin and only $1 \frac{1}{2} \mathrm{hr}$ of beating, and for paper $R_{1}$, with 1 percent of resin and $5 \frac{1}{2} \mathrm{hr}$ of beating.

The graph shows the important degree to which resin bonding in this type of fiber furnish produces strength, without the objectionable effects of hydration on expansion, oil resistance, and increased tendency to curl. The importance of these properties in printing papers is well known.

The resistance of the surface to picking, as measured by the wax test, is an important property in offset papers. The surface fibers must resist the strong pull of tacky inks in printing. Figure 3, shows the relationship between the surface pick of the sulfite-soda papers and the tendency to curl. One advantage of resin bonding is demonstrated rather clearly here.

For the papers made of 75-percent-soda-25percent-sulfite furnish, resin bonding was a rela-

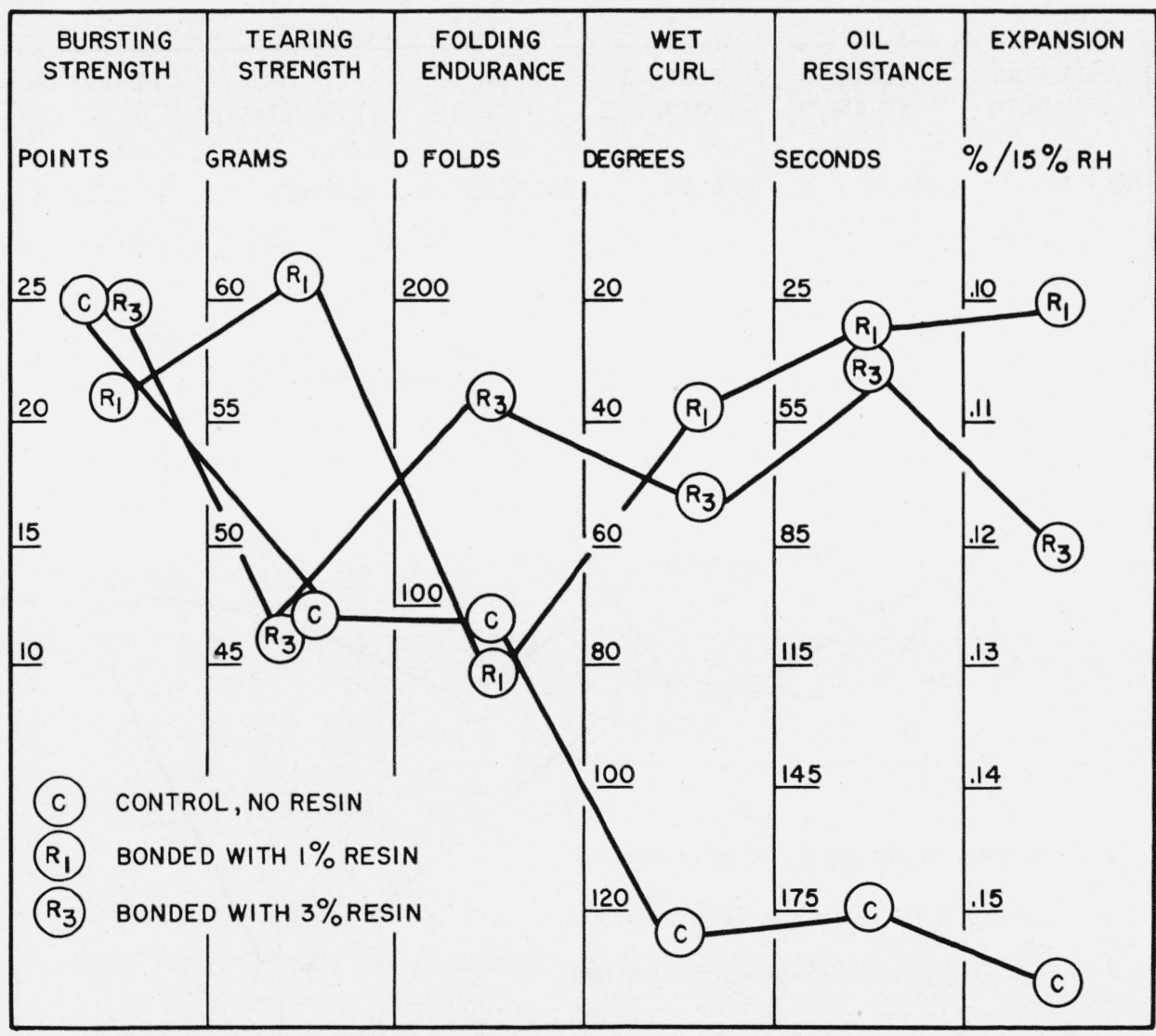

FIGURE 2. Relative properties of papers having comparable bursting strength developed by: $91 / 2$ hr of beating $(C)$; $51 / 2 h r$ of beating plus 1 percent of resin $\left(R_{1}\right)$; and $1 \frac{1}{2} \mathrm{hr}$ of beating plus 3 percent of resin $\left(R_{3}\right)$.

Seventy-five-percent-sulfite-25-percent-soda papers. 


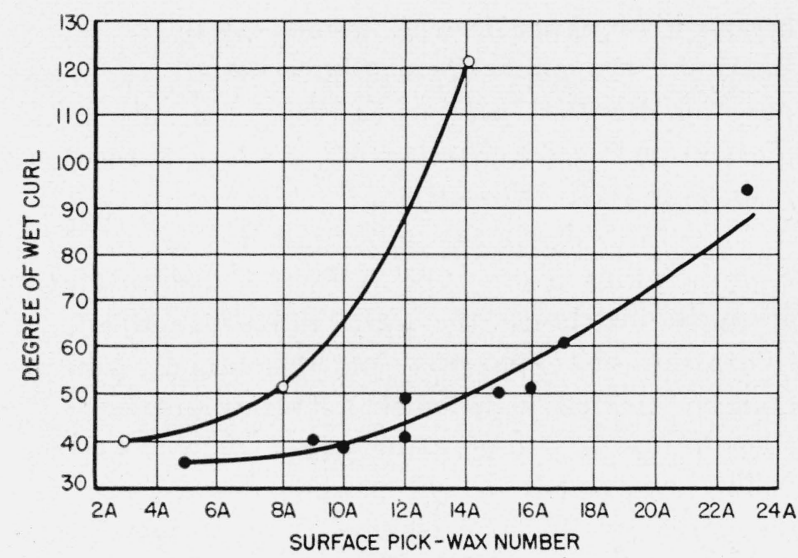

FIgURE 3. Relationship between surface pick and tendency to curl for 75-percent-sulfite-25-percent-soda papers, strength developed by beating alone and by resin bonding.

$\mathrm{O}$, No resin; $\bullet$ resin bonded.

tively greater aid to strength development than with higher sulfite content. The effects of resin bonding with this furnish are shown in figure 4 .
Beating intervals of $5 \frac{1}{2}$ hours with 1 percent of resin, and only $1 \frac{1 / 2}{2}$ hours with 2 percent of resin, produced papers superior in strength, oil absorption, and tendency to curl to the control paper with maximum beating time. With this type of furnish, hydration plays a smaller part than when more sulfite is present, consequently excessive beating has less deleterious effect on expansion. It does, however, produce excessive curl to about the same degree as with the papers containing 75 percent of sulfite. Hence, the tendency to curl accompanying excessive beating cannot be ascribed entirely to hydration. The "fines" formed in the beater doubtless play an important part.

Deciduous-wood sulfite pulp hydrates very little during beating, and the papers containing 75 percent of this pulp developed strength very slowly with beating. The effects of resin bonding are shown in figure 5. It is of interest that here again drastic beating had little effect on expan-

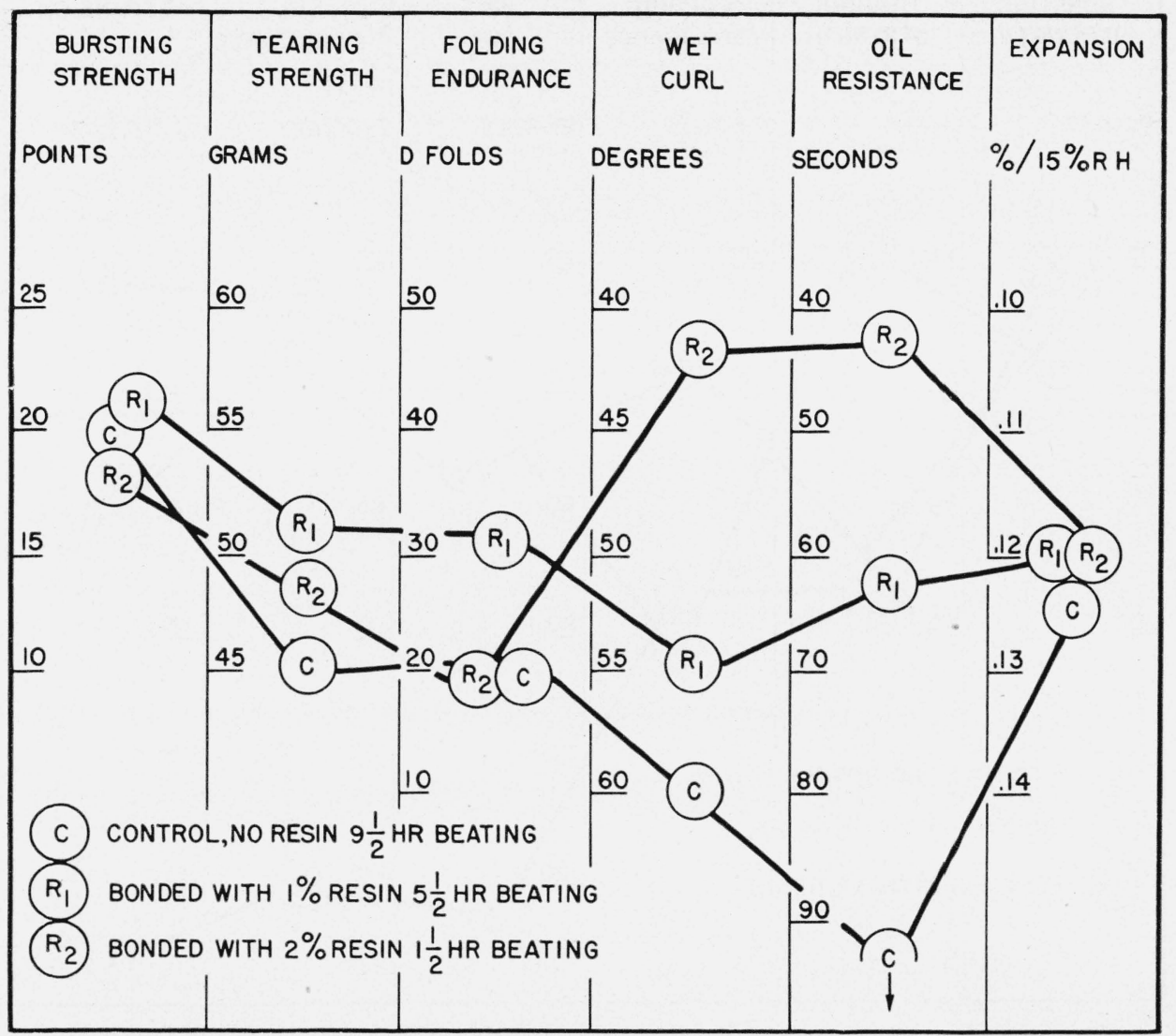

FIGURE 4. Relative properties of 75-percent-soda-25-percent-sulfite papers of comparable bursting strength, with and without resin bonding. 


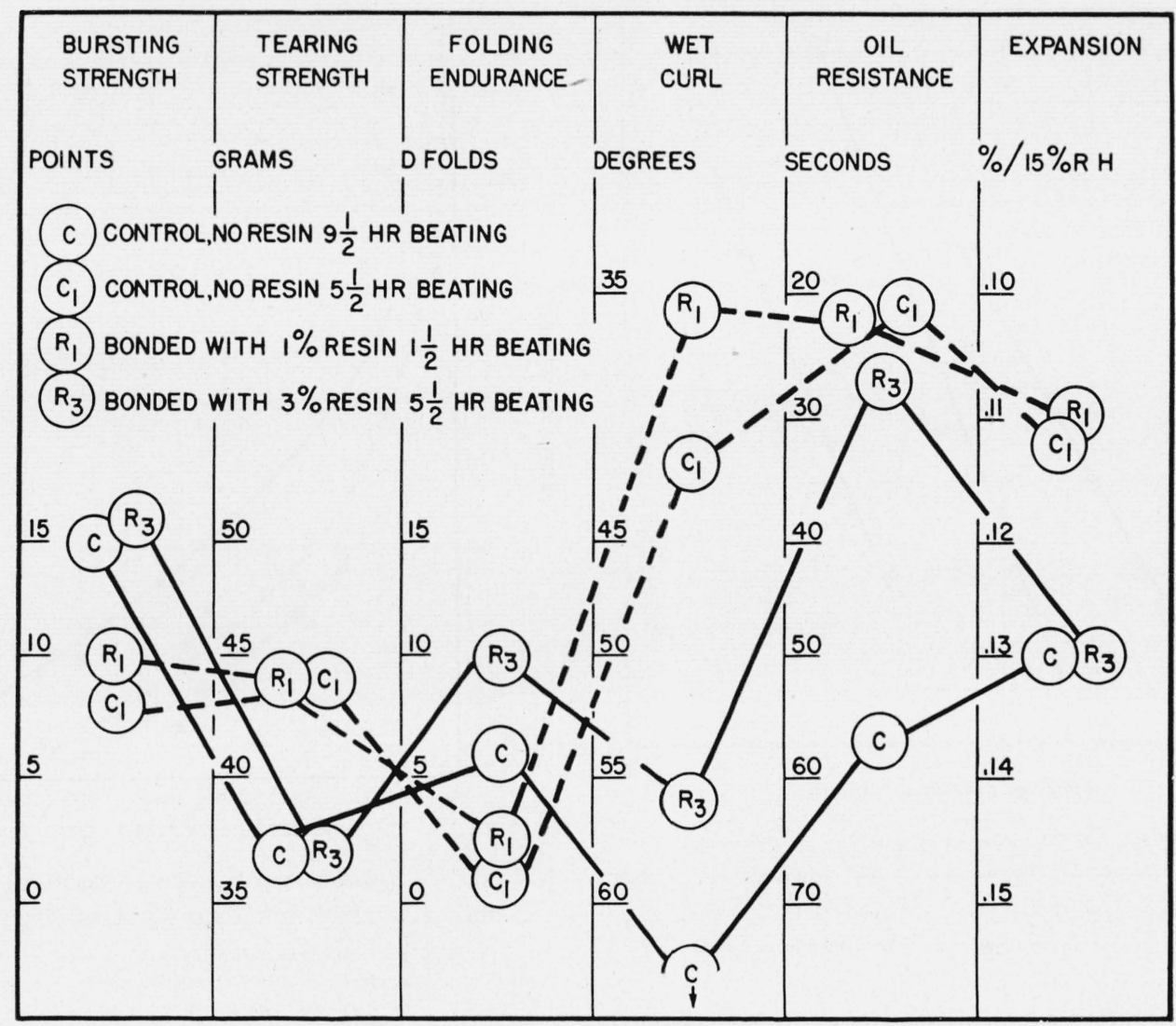

FIGURE 5. Relative properties of papers containing 75-percent deciduous-wood sulfite of comparable bursting strength developed with and without bonding resin.

sion, which is closely associated with hydration. Beating $9 \frac{1}{2}$ hours without bonding resin and $5 \frac{1}{2}$ hours with 3 percent of resin produced papers with comparable strength as did beating $5 \frac{1}{2}$ hours without resin and $1 \frac{1}{2}$ hours with 1 percent of

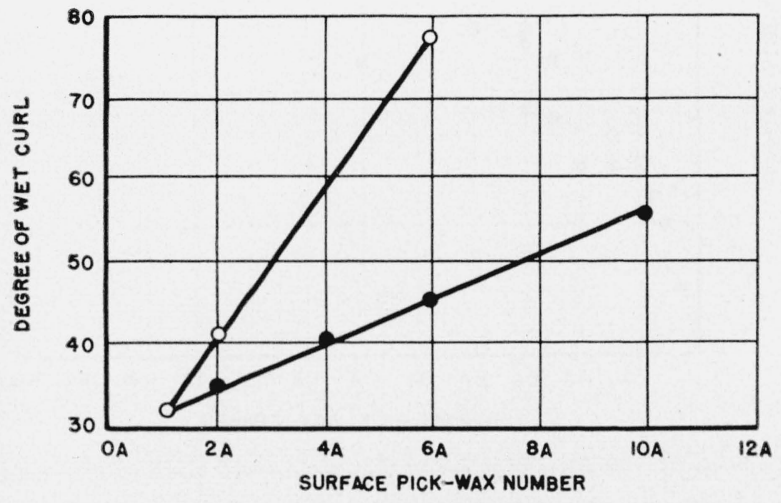

FiguRE 6. Effects of increasing resistance to surface pick on tendency to curl resin bonding versus hydration.

Fiber furnish: 75-percent deciduous-wood sulfite; 25-percent-standard sulfite. $\bigcirc$, No resin;, resin-bonded. resin. In both instances the resin-bonded paper had more desirable oil resistance and curling characteristics. This difference is illustrated in figure 6 . The straight-line relationships in this graph, as compared to the curves in figure 3 , are doubtless accounted for by the relative absence of hydration in beating deciduous-wood sulfite.

Further evidence of the different effects of hydration on these two furnishes are indicated in figure 7. This shows that bursting-strengthexpansivity relationships fall on the same straight line regardless of how the strength was developed, in the instance of deciduous-wood papers, which do not hydrate readily. The conventional 75percent sulfite-25-percent-soda papers form two straight lines, parallel but separated by approximately 8 points of burting strength. Thus a resin-bonded paper of this type with a burst of 25 points has no greater expansion than the gelbonded control paper with a bursting strength of only 17 points. 


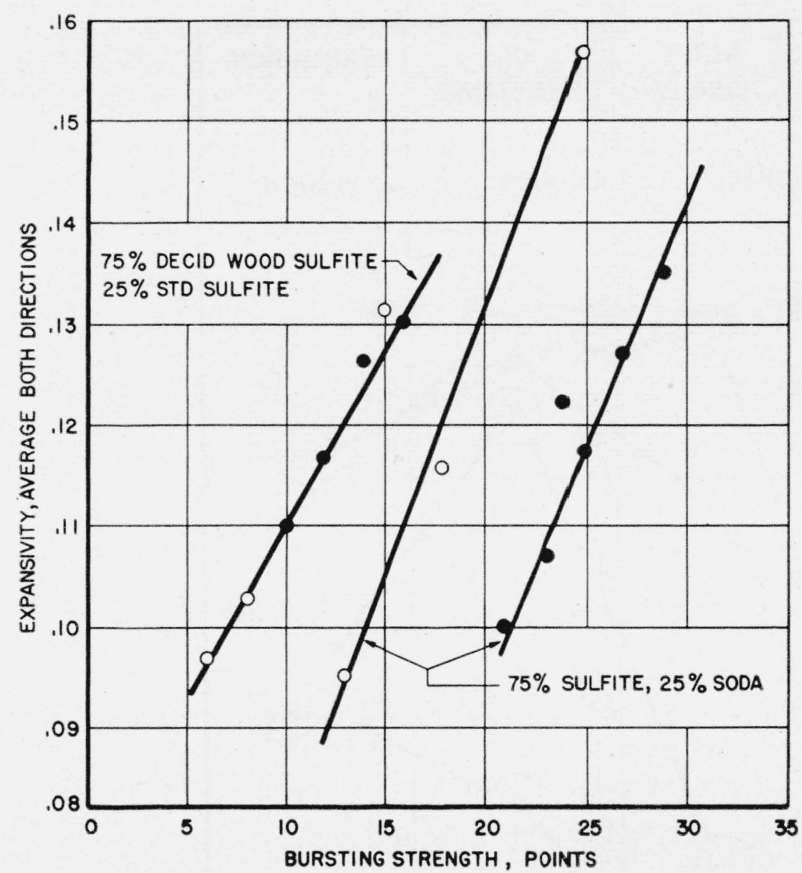

FIGURE 7. Bursting-strength-expansivity relationships for two different types of furnishes, with and without resin bonding.

, Blank, no resin; with resin bonding.

The permeability of paper to air is an important property when considering printing papers, mainly because it determines the behavior of the sheet with respect to curl and oil absorption. It has been noted that the three types of papers dealt with developed curl rapidly with increased beating, regardless of the rate of strength increase or apparent hydration. This is probably the result of "closing the sheet" or reducing the voids, whether it is by gel-formation, as in hydration of sulfite, or the formation of fines as in the instance of the filler pulps, soda and deciduous-wood sulfite, which are not readily hydrated. The relationship between permeability to air and degree of curl are shown in figure 8.

High resistance to pick is essential in offset printing papers. The surface fibers must resist the pull necessary to transfer tacky ink from the rubber blanket to the paper without lifting or being themselves transferred to the blanket. A fiber or bundle of fibers loosened by the pull of the ink not only leaves a blemish in the printed image on the sheet where the "picking" occurs, but it clings to the blanket where it becomes moistened and repels ink to print white spots on succeeding

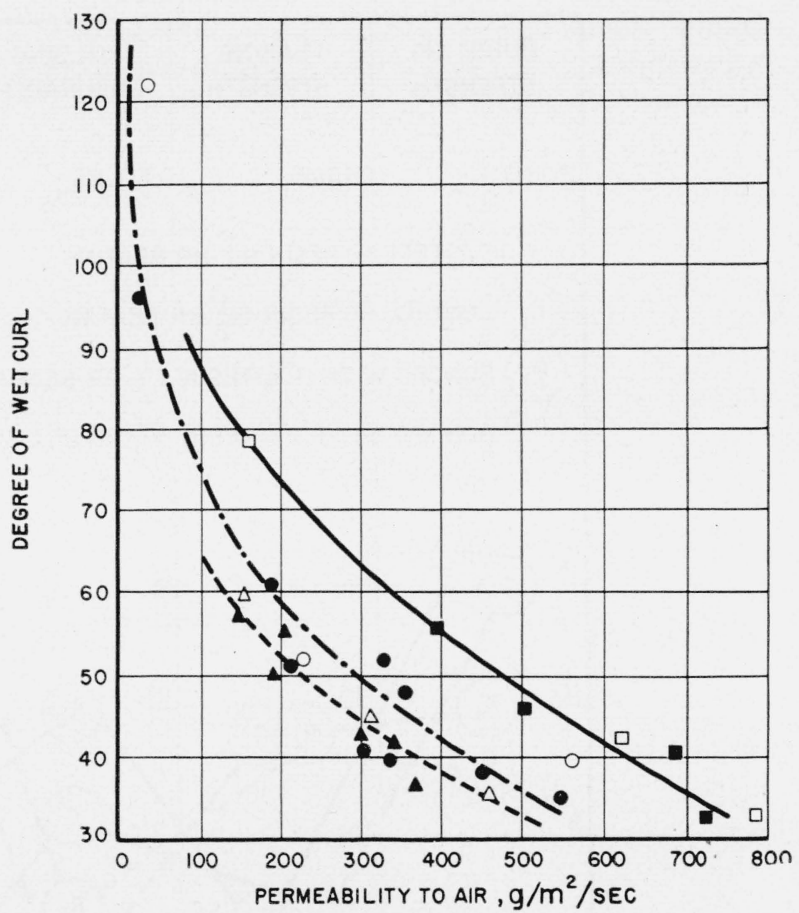

Figure 8. Relationship between permeability to air (porosity), and tendency to curl; all experimental papers.

bonded. - , 25-percent sulfite-75-percent soda; $\triangle$, no resin; $\mathbf{\Delta}$, resinbonded. -, 75-percent deciduous-wood sulfite, 25-percent sulfite (standard); $\square$, no resin; $\mathbf{\square}$, resin bonded.

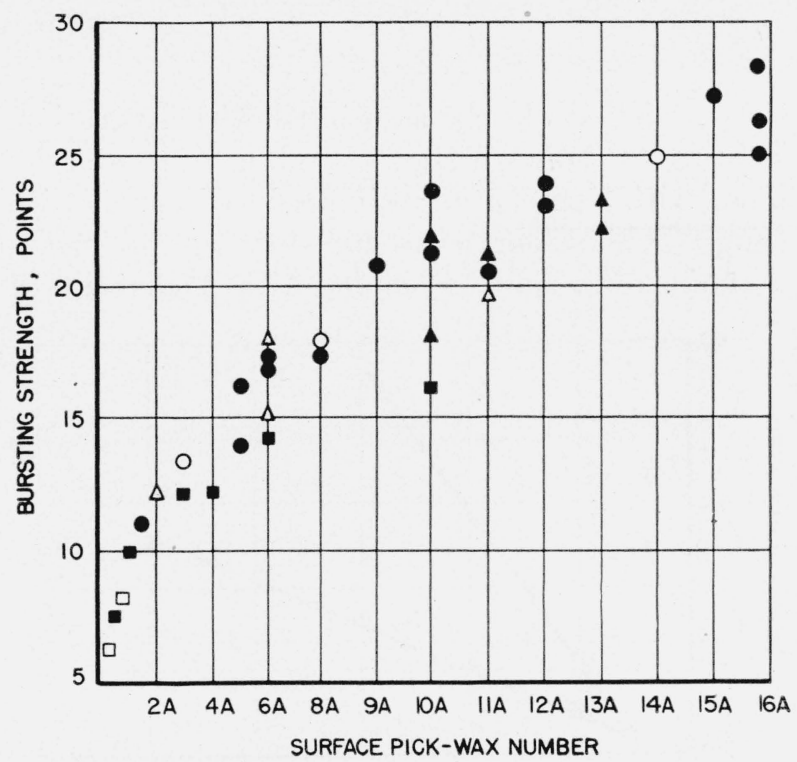

FIGURE 9. Relation of resistance to surface pick to bursting strength; all experimental papers.

$\square$, Seventy-five-percent-deciduous-wood sulfite, 25-percent-standard sulfite, no resin; $\mathbf{n}$, same resin bonded. $\bigcirc$, Seventy-five-percent sulfite-25-percentsoda, no resin; - , same resin bonded. $\triangle$, Seventy-five-percent soda-25. percent sulfite, no resin; $\boldsymbol{\Delta}$, same resin bonded. 
sheets. Surface strength is closely allied to bursting strength (see fig. 9), and is improved to about the same degree by resin bonding. The results of printing tests are shown in the two right-hand columns of table 2. It will be seen that a pick test of less than $6 \mathrm{~A}$ resulted in some picking on the press and gave feeder trouble, apparently because of a "limpness." The printing was otherwise satisfactory, except for misregister that accompanied feeder trouble.

\section{Summary and Conclusions}

By adding 1 to 3 percent of melamine formaldehyde resin, maximum strength and resistance to surface picking was developed in offset papers with a minimum of beating. The development of high strength by hydration or gel-formation affects adversely such properties as expansivity, curling, and oil absorption, which are particularly important in offset printing.

The bonding resin was very effective in developing strength in papers containing high percentages of soda and deciduous-wood sulfite pulps, which do not develop strength readily by beating alone. As little as 2 percent of resin, with a minimum of beating produced strength and surface bonding superior to any obtained without resin, even with the maximum of beating.

Using three different wood-fiber furnishes, considerably better all-around printing papers were obtained with resin-bonding than without, and the indicated savings of beating time and power were important.

The application of resin bonding apparently provides a means of using higher contents of short filler-types of fibers than is possible when developing strength by beater action only. This is important from the standpoint of conservation of fibrous raw materials and availability of pulps. The short-fibered pulp woods are not fully utilized, while the supply of long-fibered softwoods is becoming critical.

\section{References}

[1] C. G. Weber and R. M. Cobb, BS J. Research 9, 427 (1940) RP480.

[2] C. G. Weber and L. W. Snyder, BS J. Research 12, 53 (1934) RP633.

[3] C. G. Weber, J. Research NBS 13, 609 (1934), RP730.

[4] C. G. Weber and M. N. Geib, J. Research NBS 16, 93 (1936) RP859.

[5] C. G. Weber, Paper Trade J. 109, 205 (Oct. 19, 1939).

[6] C. G. Weber, Air conditioning in printing, Refrigerating Data Book, chap. 56 (Society of Refrigerating Engineers, New York, N. Y., 1940).

[7] C. G. Weber and M. N. Geib, Method of conditioning paper for multicolor offset printing, Tech. Bul. 3 (Lithographic Technical Foundation, Inc., New York, N. Y., 1940).

[8] C. G. Weber, Paper Trade J. 112, 119 (March 6, 1941).

[9] C. G. Weber, M. B. Shaw, M. N. Geib, and M. J. O'Leary, J. Research NBS 28, 241 (1942) RP1455.

[10] C. G. Weber, M. B. Shaw, and M. J. O'Leary, J. Research NBS 30, 267 (1943) RP1532.

[11] M. B. Shaw and G. W. Bicking, Tech. Pap. BS 21, 338 (1927) T340.

[12] M. B. Shaw and G. W. Bicking, BS J. Research 3, 904 (1929) RP121.

[13] M. B. Shaw, Paper Trade J. 89, No. 19, 60 (1929).

[14] F. T. Carson, BS J. Research 12, 567 (1934) RP681.

Washington, January 9, 1948. 